\title{
Haemodynamic effects of atrial pacing in rheumatic mitral stenosis
}

\author{
Subhash C. Manchanda, Lingamneni Ramesh, and Sujoy B. Roy \\ From the Department of Cardiology, All India Institute of Medical Sciences, New Delhi, India
}

\begin{abstract}
Haemodynamic effects of right atrial pacing were studied in 12 patients (average age 25.6 years) with isolated rheumatic mitral stenosis in normal sinus rhythm. The cardiac output, systemic arterial pressure, and the left ventricular work did not change during atrial pacing. Both the ventricular end-diastolic pressures and the stroke work decreased in all patients. Simultaneous increase in pulmonary arterial wedge pressures increased the left atrioventricular diastolic pressure gradients significantly. A pronounced fall in left ventricular stroke work concomitant with a decrease in left ventricular end-diastolic pressure during atrial pacing probably indicates normal left ventricular function in all patients. These results are different from those obtained by others and this may be because the patients were younger.
\end{abstract}

Although right atrial pacing has been extensively employed as a valuable tool to study the haemodynamic effects of increase in heart rate in normal and various disease states (Ross, Linhart, and Braunwald, 1965; Samet et al., 1965; Stein et al., I966; Sowton et al., 1967; Frick et al., 1968; Benchimol and Goldstein, 1969; Parker et al., 1969; Cheng, 197 ; Linhart, 1971a, 1972), its effects in rheumatic mitral stenosis have not been adequately studied. Moreover, no such study has been reported from India, where the clinical and haemodynamic profiles of rheumatic mitral stenosis appear to be somewhat different from those of Western countries (Roy et al., 1963; Cherian et al., 1964; Sen et al., 1966). Accordingly, the present investigation was designed to study the haemodynamic effects of increasing the heart rate by right atrial pacing in patients with rheumatic mitral stenosis.

\section{Subjects and methods}

Twelve patients ( 7 men and 5 women) with isolated rheumatic mitral stenosis in normal sinus rhythm were studied. Their ages ranged between 16 and 34 years (average of 25.6 years). None of the patients had evidence of rheumatic activity as judged by the modified Jones criteria (1965). No one was receiving digitalis preparations for at least two weeks before the study. A right and percutaneous left heart catheterization study (Seldinger, 1953) was performed in all in a fasting state

Received 9 November 1973. without any premedication, to assess the severity of mitral stenosis and to exclude mitral regurgitation. The nature of the procedure of right atrial pacing was fully explained to each patient and a written consent was taken for carrying out the procedure of atrial pacing in addition to right and left heart catheterization. Intracardiac pressures were recorded through P23 AA strain gauge transducers on a multichannel photographic recorder (DR-8 Electronic for Medicine Inc. U.S.A.). The baseline for all pressure measurements was taken as half the chest thickness at the second costal cartilage in the supine position (Roy, Gadboys, and Dow, 1957). Cardiac output was estimated by a dye dilution technique (Hamilton et al., 1932). Indirect transmitral pressure gradients were obtained by simultaneous recording of pulmonary artery wedge pressure and left ventricular diastolic pressures using equisensitive preamplifiers with a common baseline. The precise point where left ventricular end-diastolic pressure was measured corresponded with the nadir of the atrial kick in the left ventricular tracing. In tracings where the atrial kick could not be clearly defined, the left ventricular enddiastolic pressure was measured at a point corresponding with the peak of the $R$ wave in the surface electrocardiogram. A No. 6F NBIH bipolar catheter was introduced percutaneously through a venous dilator into the right femoral vein and positioned in the right atrium at a site where complete capture occurred during pacing with an external fixed rate pacemaker. Atrial pacing was performed at a minimum rate of 30 per cent above the resting heart rate. In 3 patients where the basal heart rate was less than 90 a minute, pacing was performed at two rates, one 30 per cent above the basal level and the other at the maximum rate of 140 a minute. All the haemodynamic variables were repeated during 8 to ro minutes 
of effective pacing. The various calculated parameters were obtained as follows:

I. Stroke index $\left(\mathrm{ml} /\right.$ beat per $\left.\mathrm{m}^{2}\right)=\frac{\text { cardiac index }(\mathrm{ml} / \mathrm{min} \text { per }}{\text { heart rate (beats } / \mathrm{min})}$

Arterial mean pressure $(\mathrm{mmHg})$ - atrial mean

2. Vascular resistance (units) pressure $(\mathrm{mmHg})$

3. Systolic ejection rate Cardiac index $\left(\mathrm{ml} / \mathrm{min}\right.$ per $\left.\mathrm{m}^{2}\right)$ $\left(\mathrm{ml} / \mathrm{min}\right.$ per $\left.\mathrm{m}^{2}\right)=$ Systolic ejection period $(\mathrm{sec} /$ min)

Mean left ventricular systolic pressure (mmHg) - Left Ven-

4. Left ventricular work index ( $\mathrm{kg} \mathrm{m} / \mathrm{min}$ per $\mathrm{m}^{2}$ ) tricular end - diastolic pressure $(\mathrm{mmHg}) \times$ cardiac index

$=\frac{\left(1 . / \mathrm{min} \mathrm{per}^{2}\right) \times \mathrm{I} \cdot 36}{100}$

5. Left ventricular $\begin{aligned} & \text { stroke work } \\ & \text { index }(\mathrm{g} \mathrm{m} / \text { beat }\end{aligned}=\frac{\left(\mathrm{g} \mathrm{m} / \mathrm{min} \text { per } \mathrm{m}^{2}\right)}{\text { Heart rate (beats } / \mathrm{min})}$ per $\left.\mathrm{m}^{2}\right)$

Left ventricular work index

6. Stroke power (g m/min per $\left.\mathrm{m}^{2}\right)$ $\left(\mathrm{g} \mathrm{m} / \mathrm{sec}\right.$ per $\left.\mathrm{m}^{2}\right)=\frac{\mathrm{S} \text { Systolic ejection period }}{(\mathrm{sec} / \mathrm{min})}$ $(\mathrm{sec} / \mathrm{min})$

\section{Statistical analysis}

The data were statistically analysed by the paired ' $t$ ' test (Fisher, 1958).

\section{Results (Table)}

The resting heart rate in 12 patients averaged 86 beats a minute (range 60-108 beats a minute) and the average heart rate obtained with atrial pacing was I30 beats a minute (range I08-I44 beats a minute), an increase of $5 \mathrm{I}$ per cent. The cardiac output, systemic arterial pressures, and the left ventricular work did not show significant change during atrial pacing, but the stroke index, stroke work index, systolic ejection rate, and stroke power decreased significantly. The right atrial mean pressure decreased slightly but the decrease was not statistically significant. The right ventricular enddiastolic pressure, however, decreased significantly. The pulmonary artery mean pressures increased slightly in all patients from a mean of 27.4 to $3 \mathrm{I} \cdot 8 \mathrm{mmHg}$. Because it was consistent, this increase in pulmonary arterial pressure, though small in all patients, was significant $(P<0.00 \mathrm{I})$. The pulmonary arterial wedge pressure also increased in all patients from a mean of 20.0 to

T ABLE Atrial pacing in rheumatic mitral stenosis (I 2 patients)

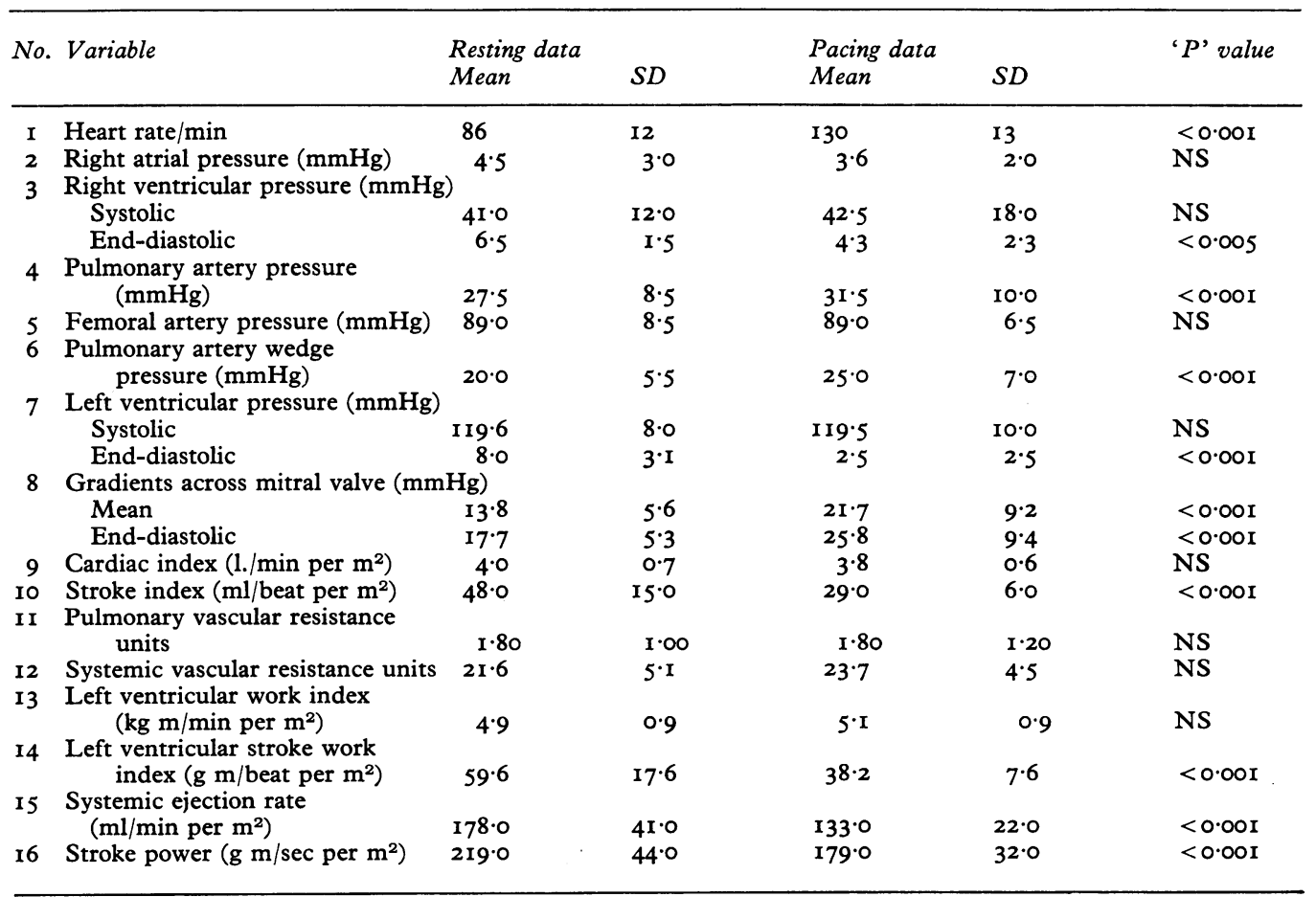




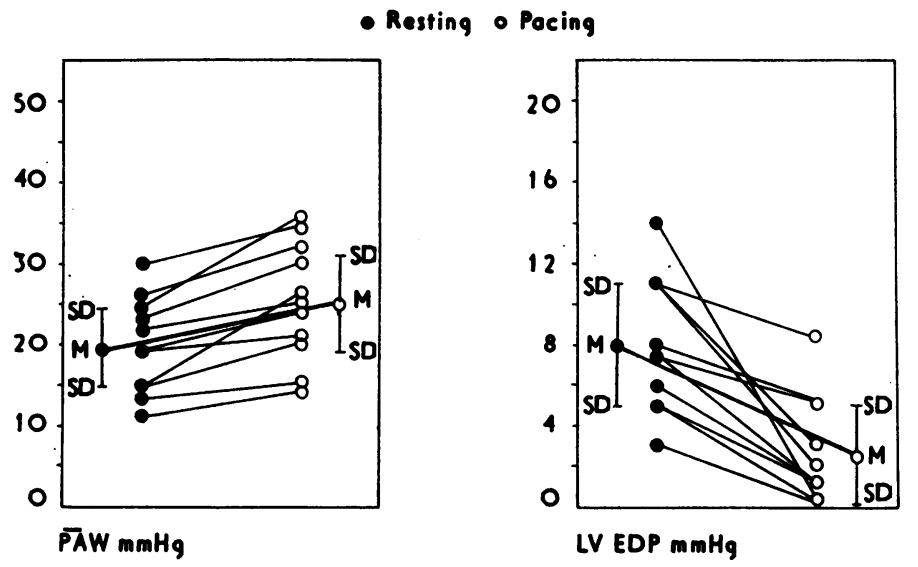

FIG. I Atrial pacing increased the pulmonary arterial wedge pressure (PAW) from a mean of $20 \cdot 0 \pm 5.5$ to $25 \cdot 0 \pm 7 \cdot 0 \mathrm{mmHg}(P<0 \cdot 001)$ and decreased the left ventricular end-diastolic pressure ( LVEDP) from a mean of $8.0 \pm 3.1$ to $2.5 \pm 2.5 \mathrm{mmHg}(P<0.001)$ in patients with mitral stenosis.

$25.0 \mathrm{mmHg}$ and the left ventricular end-diastolic pressure decreased from a mean of 8.0 to $2.5 \mathrm{mmHg}$ (Fig. I), thus resulting in a definite and pronounced increase in the mean and end-diastolic gradients between the pulmonary arterial wedge and left ventricular pressures (Fig. 2).

\section{Discussion}

The effects of right atrial pacing on cardiac output, systemic arterial pressure, pulmonary and systemic vascular resistance, systolic ejection rate, left ventricular stroke work, and stroke power as obtained in the present study are in agreement with those obtained by others in normal hearts as well as in mitral stenosis (Stein et al., 1966; Benchimol and Liggett, 1966; Parker et al., 1969; Cheng, 1971; Linhart, 1972).

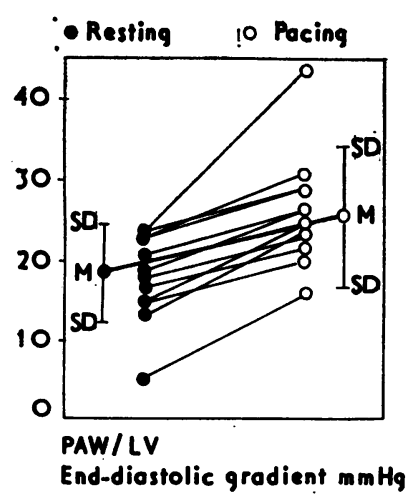

The right atrial and left ventricular filling pressures decrease as a result of atrial pacing and the pulmonary arterial wedge pressures increase significantly. If pulmonary arterial wedge pressure reflects left atrial pressure, then the increase in this pressure and a simultaneous decrease in the left ventricular end-diastolic pressure widens considerably the diastolic gradients across the mitral valve. The resting left ventricular end-diastolic pressure was normal (below $12 \mathrm{mmHg}$ ) in II of the I2 patients and mildly raised ( $14 \mathrm{mmHg}$ ) in one. The level of left ventricular end-diastolic pressure has been extensively used as a measure of left ventricular function, but it has its limitations when it is employed exclusively as an index of left ventricular function (Braunwald and Ross, 1963). During pacing, the left ventricular pressure decreased uni-

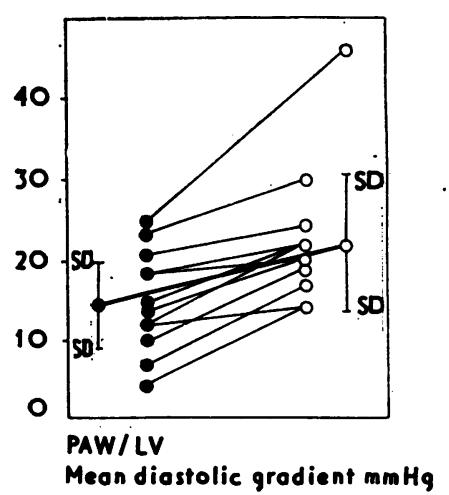

FIG. 2 The end-diastolic and mean diastolic pressure gradient between pulmonary arterial wedge $(P A W)$ and left ventricles increased significantly after atrial pacing $(P<0 \cdot 001)$. 
formly in all patients. Benchimol and Goldstein (1969) and Cheng (1971), in contrast to the present findings, observed an increase in the left ventricular end-diastolic pressure during atrial pacing in a third to half of their patients with mitral stenosis. This was considered by them as evidence of left ventricular dysfunction in their patients. However, the left ventricular diastolic pressure need not necessarily rise during atrial pacing even in the presence of gross left ventricular dysfunction (Parker, Khaja, and Case, I971; Linhart, 1971a, 1972).

Linhart (1971a, b, 1972) and Parker et al. (197I) have attempted to differentiate normal from abnormal left ventricles by constructing what they call 'pacing ventricular function curves' relating stroke work to the left ventricular end-diastolic pressure. These 'curves' are not the classic ventricular function curves because the classic curves are determined at constant heart rates (Sarnoff, 1955). Nevertheless, Linhart and Parker et al. observed that patients with normal left ventricles show a pronounced fall in stroke work concomitant with a small fall in left ventricular end-diastolic pressure in contrast to patients with left ventricular dysfunction who show slight or no decrease in stroke work with a decreased ventricular diastolic pressure. If such 'pacing ventricular function curves' are drawn in our patients, it is apparent that there is a uniform and pronounced decrease in left ventricular stroke work with a decrease in left ventricular end-diastolic pressure (Fig. 3), suggesting normal left ventricular function in all our patients. These observations differ from those of Linhart (1972) who found evidence of left ventricular dysfunction in 5 of the 13 patients with mitral stenosis by 'pacing ventricular function curves'. Left ventricular dysfunction has also been reported to be present in 3 to 100 per cent of patients with mitral stenosis studies by other techniques (Ferrer et al., 1955; Fleming and Wood, 1959; Ross and Braunwald, 1964; Feigenbaum et al., 1966; Kasalicky et al., I968; Bittar, Sosa, and Reid, 197r; Aronow, Kaplan, and Ellestad, I971 ; Curry, Elliot, and Ramsey, 1972; Hildner et al., 1972).

The reasons for the discrepancy between the present observations and those obtained by other investigators are not clear. It has, however, been reported earlier that both the clinical and haemodynamic profiles of patients with rheumatic mitral stenosis in India differ from those seen in Western countries (Roy et al., 1963; Cherian et al., 1964; Sen et al., 1966). The average age of the patients in the present study was 25.6 years. They are almost two decades younger than the groups reported by Linhart (1972) where the average age was 45 years.

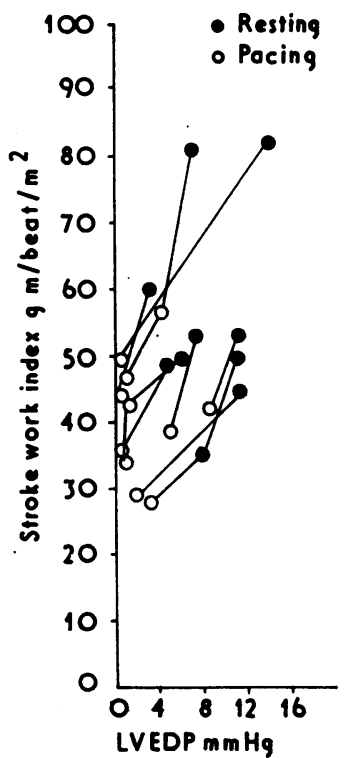

FIG. 3 'Pacing ventricular function curves' in all patients with mitral stenosis showed a pronounced decrease in left ventricular stroke work index with a concomitant fall in left ventricular enddiastolic pressure (LVEDP) after atrial pacing as seen in normal ventricles.

All the patients reported in the present study and the majority of patients with isolated mitral stenosis in an earlier study from this laboratory (Roy et al., 1963) had normal cardiac outputs in contrast to the Western investigators who have found low resting cardiac outputs in the majority of their patients with mitral stenosis (Ellis et al., I95I; Gorlin et al., 1951; Cosby et al., 1953; Wood, 1954; Ferrer et al., 1955; Soloff, Zatuchni, and Mark, 1957). Roy et al. (I963) suggested that these younger patients probably had a relatively healthy myocardium which might be responsible for the normal cardiac output. This may well be the reason for the differing haemodynamic response to right atrial pacing and 'normal' left ventricular function in patients with rheumatic mitral stenosis in the present study.

The results of the present investigation have to be interpreted guardedly because of certain inherent limitations in studying the effects of atrial pacing in mitral stenosis. Patients with atrial fibrillation cannot be studied because of the ineffectiveness of atrial pacing in such patients. Moreover, very sick patients with severe mitral stenosis were not subjected to atrial pacing because of the risk of raising the left atrial pressures to alarmingly high levels and precipitating pulmonary oedema. Nevertheless, 
some of the observations appear to be strikingly different from those reported by others (Benchimol and Goldstein, 1969; Cheng, I971 ; Linhart, 1972): these authors also did not include any patient with atrial fibrillation or who had a severe degree of mitral stenosis.

\section{References}

Aronow, W. S., Kaplan, H. A., and Ellestad, M. H. (197I). LVET/EICT index in mitral valve disease. Acta Cardiologica, 26, $\mathrm{x}$.

Benchimol, A., and Goldstein, M. R. (1969). A review of atrial pacing - clinical and laboratory applications. Annals of the New York Academy of Sciences, 167, 604.

Benchimol, A., and Liggett, M. S. (I966). Cardiac hemodynamics during stimulation of the right atrium, right ventricle and left ventricle in normal and abnormal hearts. Circulation, 33, 933.

Bittar, N., Sosa, J. A., and Reid, E. A. S. (197I). Left ventricular function during exercise in patients with pure mitral stenosis. Acta Cardiologica, 26, 581.

Braunwald, E., and Ross, J., Jr. (1963). The ventricular enddiastolic pressure. Appraisal of its value in the recognition of ventricular failure in man. American fournal of Medicine, 34, 147 .

Cheng, T. O. (197I). Atrial pacing: its diagnostic and therapeutic applications. Progress in Cardiovascular Diseases, 14, 230.

Cherian, G., Vytilingam, K. I., Sukumar, I. P., and Gopinath, N. (1964). Mitral valvotomy in young patients. British Heart fournal, 26, 157.

Cosby, R. S., Griffith, G. C., Levinson, D. C., Zinn, W. J., Oblath, R. W., Dimitroff, S. P., and Herman, L. M. (1953). The physiologic evaluation of patients before and after mitral commisurotomy. Diseases of the Chest, 23, 499.

Curry, G. C., Elliot, L. P., and Ramsey, H. W. (1972). Quantitative left ventricular angiographic findings in mitral stenosis. American fournal of Cardiology, 29, 621 .

Ellis, L. B., Bloomfield, R. A., Graham, G. K., Greenberg, D. J., Hultgren, H. N., Kraus, H., Maresh, G., Mebane, J. G., Pfeiffer, P. H., Selverstone, L. A., and Taylor, J. A. (195I). Studies in mitral stenosis. Archives of Internal Medicine, 88, 515 .

Feigenbaum, H., Campbell, R. W., Wunsch, C. M., and Steinmetz, E. F. (1966). Evaluation of the left ventricle in patients with mitral stenosis. Circulation, 34, 462.

Ferrer, M. I., Harvey, R. M., Wylie, R. H., Himmelstein, A. Lambert, A., Kuschner, M., Cournand, A., and Richards, D. W. (1955). Circulatory effects of mitral commissurotomy with particular reference to selection of patients for surgery. Circulation, 12, 7.

Fisher, R. A. (1958). Statistical Methods for Research Workers, 13th ed. Oliver and Boyd, Edinburgh.

Fleming, H. A., and Wood, P. (1959). The myocardial factor in mitral valve disease. British Heart fournal, 21, I 17.

Frick, M. H., Balcon, R., Cross, D., and Sowton, E. (1968). Hemodynamic effects of nitroglycerin in patients with angina pectoris studied by an atrial pacing method. Circulation, 37, 160.

Gorlin, R., Haynes, F. W., Goodale, W. T., Sawyer, C. G., Dow, J. W., and Dexter, L. (I95I). Studies of the circulatory dynamics in mitral stenosis II. Altered dynamics at rest. American Heart fournal, 4I, 30.

Hamilton, W. F., Moore, J. W., Kinsman, J. M., and Spurling, R. G. (1932). Studies on circulation IV. Further analysis of the injection method, and of changes in hemo- dynamics under physiological and pathological conditions. American fournal of Physiology, 99, 534.

Hildner, F. J., Javier, R. P., Cohen, L. S., Samet, P., Nathan, M. J., Yahr, W. Z., and Greenberg, J. J. (1972). Myocardial dysfunction associated with valvular heart disease. American fournal of Cardiology, 30, 319.

Jones Criteria (Revised) for the guidance in the diagnosis of rheumatic fever (1965). Circulation, 32, 664

Kasalicky, J., Hurych, J., Widimsky, J., Dejdar, R., Metys, R., and Stanek, V. (1968). Left heart haemodynamics at rest and during exercise in patients with mitral stenosis. British Heart fournal, 30, 188.

Linhart, J. W. (1971a). Myocardial function in coronary artery disease determined by atrial pacing. Circulation, 44, 203.

Linhart, J. W. (I97Ib). Pacing-induced changes in stroke volume in the evaluation of myocardial function. Circulation, 43, 253.

Linhart, J. W. (1972). Atrial pacing in the determination of myocardial function in patients with mitral stenosis. Chest, 6r, 134 .

Parker, J. O., Khaja, F., and Case, R. B. (1971). Analysis of left ventricular function by atrial pacing. Circulation, 43, 24I.

Parker, J. O., Ledwich, J. R., West, R. O., and Case, R. B. (1969). Reversible cardiac failure during angina pectoris. Hemodynamic effects of atrial pacing in coronary artery disease. Circulation, 39, 745.

Ross, J., Jr. and Braunwald, E. (1964). Study of left ventricular function in man by increasing resistance to ventricular ejection with angiotensin. Circulation, 29, 739.

Ross, J., Jr., Linhart, J. W., and Braunwald, E. (1965). Effect of changing heart rate in man by electrical stimulation of the right atrium. Studies at rest, during exercise and with isoproterenol. Circulation, 32, 549.

Roy, S. B., Bhatia, M. L., Lazaro, E. J., and Ramalingaswami, V. (1963). Juvenile mitral stenosis in India. Lancet, 2, 1193.

Roy, S. B., Gadboys, H. L., and Dow, J. W. (1957). Base line for left heart catheterization. American Heart fournal, 54, 753.

Samet, P., Bernstein, W. H., Levine, S., and Lopez, A. (1965). Hemodynamic effects of tachycardias produced by atrial and ventricular pacing. American fournal of Medicine, 39, 905.

Sarnoff, S. J. (1955). Myocardial contractility as described by ventricular function curves; observations on Starling's law of the heart. Physiological Reviews, 35, 107.

Seldinger, S. I. (1953). Catheter replacement of the needle in percutaneous arteriography. Acta Radiologica, 39, 368.

Sen, P. K., Panday, S. R., Parulkar, G. B., and Biswas, P. K. (1966). Mitral stenosis in the young. Diseases of the Chest, $49,384$.

Soloff, L. A., Zatuchni, J., and Mark, G. E. (1957). Myocardial and valvular factors in rheumatic heart disease with mitral stenosis. American fournal of the Medical Sciences, $233,518$.

Sowton, G. E., Balcon, R., Cross, D., and Frick, M. H. (1967). Measurement of the angina threshold using atrial pacing. Cardiovascular Research, 1, 301.

Stein, E., Damato, A. N., Kosowsky, B. D., Lau, S. H., and Lister, J. W. (I966). The relation of heart rate to cardiovascular dynamics; pacing by atrial electrodes. Circulation, 33, 925.

Wood, P. (1954). An appreciation of mitral stenosis. British Medical fournal, $\mathrm{r}, \mathrm{I} 05 \mathrm{I}$ and $1 \mathrm{I} 13$.

Requests for reprints to Professor Sujoy B. Roy, Department of Cardiology, All India Institute of Medical Sciences, New Delhi-r roor6, India. 